\title{
Functional morphology of a highly specialised pivot joint in the cranio-cervical complex of the minute lizard Ablepharus kitaibelii in relation to feeding ecology and behaviour
}

\author{
Nikolay Natchev ${ }^{1,2,7}$, Nikolay Tzankov ${ }^{3}$, Vladislav Vergilov ${ }^{4}$, Stefan Kummer ${ }^{5}$, Stephan Handschuh ${ }^{5,6}$ \\ ${ }^{1}$ Department Integrative Zoology, University of Vienna, Althanstrasse 14, 1090 Vienna, Austria \\ ${ }^{2}$ Faculty of Natural Science, Shumen University, Universitetska 115/313, 9700 Shumen, Bulgaria \\ ${ }^{3}$ Section Vertebrates, National Museum of Natural History, Bulgarian Academy of Sciences, Tzar Osvoboditel 1, \\ 1000 Sofia, Bulgaria \\ ${ }^{4}$ Department of Anthropology and Zoology, Sofia University, Dragan Tzankov 8, 1164 Sofia, Bulgaria \\ ${ }^{5}$ VetCore Facility for Research, University of Veterinary Medicine Vienna, Veterinärplatz 1, 1210 Vienna, Austria \\ ${ }^{6}$ Department of Theoretical Biology, University of Vienna, Althanstrasse 14, 1090 Vienna, Austria \\ ${ }^{7}$ E-mail: nikolay.natchev@univie.ac.at
}

Key words: evolution, feeding, neck, odontoid, parallel, skink, $\mu \mathrm{CT}$

\begin{abstract}
The snake-eyed skink Ablepharus kitaibelii is one of the smallest European lizards, but despite its minute size it is able to feed on comparatively large prey. Here we investigate the diet of $A$. kitaibelii and the mechanisms that allow the skink to overpower relatively large and even noxious prey. High-speed cinematography showed that $A$. kitaibelii uses a series of shaking and battering movements to immobilise and kill prey prior to swallowing. During this process, the skinks rises up on the hind limbs and then whacks the prey sidewise on the substrate by twisting the trunk, neck and head laterally. Our analysis showed that the shaking kinematics is very uniform among the investigated specimens. The morphological investigation of the cranio-cervical system revealed that A. kitaibelii possesses a well-developed synovial joint between the odontoid process of the axis, the atlas, and the basioccipital. The odontoid process is cylindrical and slim and together with the atlas and the basioccipital it forms a highly specialised pivot joint for lateral head rotation. We propose that the occipito-atlanto-axial complex of A. kitaibelii represents a functional adaptation for additional stabilisation of the cranio-cervical complex during prey shaking. Digital data from morphological databases showed that specialised joints of this type are very rare, but do also occur in other squamate groups. Thus we hypothesise that specialised cranio-cervical joints have evolved parallel as functional adaptations to different feeding and locomotion patterns. Future studies that link feeding kinematics and locomotion to cranio-cervical morphology might elucidate the function of various specialised occipito-atlanto-axial systems of squamates.
\end{abstract}

\section{Contents}

Introduction ........................................................................................................... 13

Material and methods ……................................................................. 15

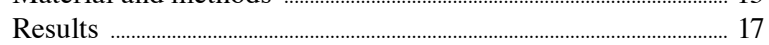

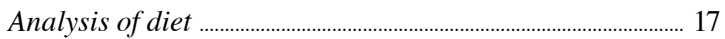

Feeding kinematics ........................................................................... 17
Morphology of the cranio-cervical-joint .................................... 17

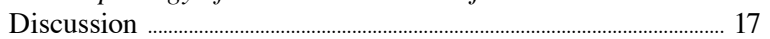

Analysis of diet ............................................................................................ 17

Feeding kinematics and morphology of the

cranio-cervical-joint ......................................................................... 18

Differences in cranio-cervical morphology

between major squamate groups ………………………............ 19



Acknowledgements ............................................................................................ 21

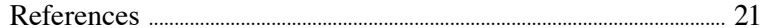

\section{Introduction}

Feeding behaviour and performance during food uptake, intraoral transport (including chewing and puncture crushing) and deglutition have been thoroughly investigated in lizards (Schwenk, 2000; Herrel et al., 2001a, 2007; Ross et al., 2007). Besides the ongoing debate on the utilisation of venom in lizards (Herrel et al., 1997; Fry et al., 2006, 2009, 2010; Fry and Scheib, 2007; Weinstein et al., 2009), several strategies for mechanical killing and immobilising of prey are described to date for this group. Nonophidian lepidosaurs kill prey by biting, suffocating, shaking or crushing, and dragging it against the substrate (Schwenk, 2000). Varanus exanthematicus (Bosc, 1792) utilises a number of bites to kill a mouse, but it also shakes and hits the prey against the substrate or against objects (Smith, 1982). A very similar behaviour was reported for $\mathrm{Va}$ ranus salvator (Laurenti, 1768) (Honegger and Heusser, 1969; Dauth, 1983). The leopard lizard, Gambelia wislizenii (Baird and Girard, 1852), processes noxious prey by increasing gape cycle frequencies (Lappin and German, 2005). 

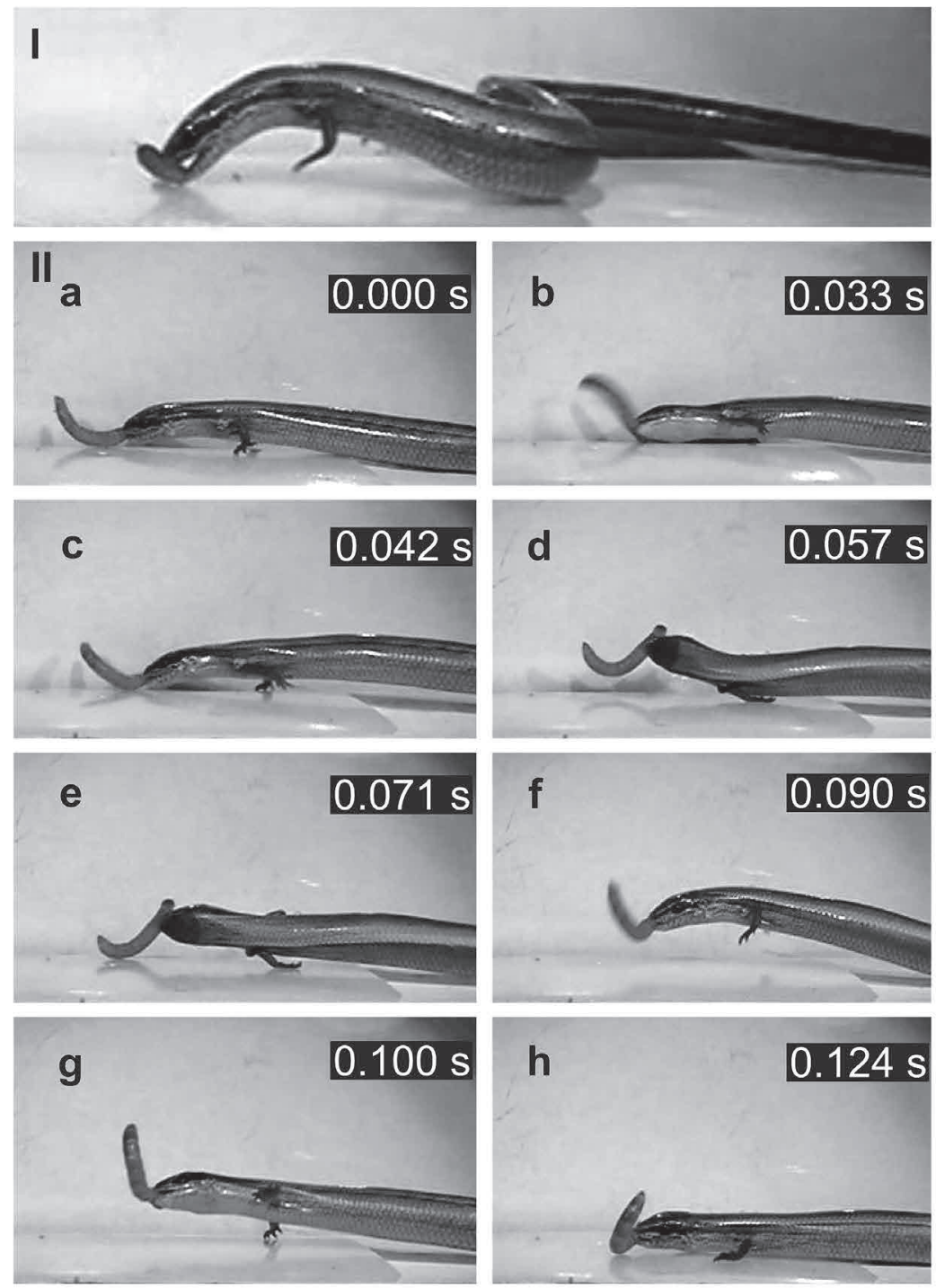

Fig. 1. Kinematics of prey capture and immobilization in Ablepharus kitaibelii. (I) Selected frame from a prey capture sequence in A. kitaibelii. (II) Selected sequence representing a prey shaking cluster (a-h). Time in seconds (s).
Some lizards rely on hard bites for killing. The teiid Tupinambis teguixin (Linnaeus, 1758) smashes its prey by crushing bites with a maximum bite force over $100 \mathrm{~N}$ (McBrayer and White, 2002). Similarly, molluscivorous lizards use repetitive crushing bites to break the shell of snails, applying even higher bite forces of more than 400N (Schaerlaeken et al., 2012). The scincid Tiliqua rugosa (Gray, 1825) crushes snails and mice by prolonged bursts of all jaw-closing muscles (Herrel et al., 1999b).

Another behaviour of nonophidian lepidosaurs to immobilise prey is 'prey-shaking' or 'death-shaking' (Dauth, 1983, 1986). The tokay gecko Gekko gecko (Linnaeus, 1758) shakes and hits pray against the substrate until it becomes completely motionless (Roloff,
1957). The much smaller five-lined skink Plestiodon fasciatus (Linnaeus, 1758), was observed to catch large prey by biting and to immobilise it by lateral shaking and by battering it against a rock ledge (Fitch, 1954).

The species investigated here, the European snakeeyed skink Ablepharus kitaibelii (Bibron and Bory de Saint-Vincent, 1833), is even smaller than P.fasciatus, but feeds on relative large butterflies, cicadas and even on noxious spiders (Herczeg et al., 2007) and chilopods (see results). The present study addresses the strategies, which allow A. kitaibelii to subdue large prey. In lizards, bite force is strongly correlated with overall body size (da Silva et al., 2014) and the size and shape of the head (for an overview see Anderson et al. (2008)). Lizards with larger heads possess more voluminous ad- 
Table 1. Diet of the snake-eyed skink. Food spectrum of Ablepharus kitaibelii according to the three methods of research, *n- number of studied excrements, $\mathrm{n}$ - number of studied individuals.

\begin{tabular}{lccllll}
\hline & \multicolumn{2}{c}{ This study } & \multicolumn{2}{c}{ Angelov et al. (1966) } & Herczeg et al. (2007) \\
\hline Orders & $*_{n}$ & $\%$ (total) & $n$ & $\%$ (total) & $n$ & $\%$ (total) \\
\hline Araneae & 7 & 23.3 & 6 & 25 & 25 & 18.5 \\
Lithobiomorpha & 2 & 6.7 & - & - & - & - \\
Hymenoptera & 3 & 10 & 2 & 8.3 & 20 & 14.8 \\
Coleoptera & 2 & 6.7 & 6 & 25 & 23 & 17 \\
Hemiptera & 12 & 40 & 5 & 20.9 & 50 & 37 \\
Diptera & 1 & 3.3 & 1 & 4.2 & 5 & 3.7 \\
Pseudoscorpiones & - & - & 2 & 8.3 & 3 & 2.2 \\
Lepidoptera & - & - & 2 & 8.3 & 9 & 6.6 \\
Other & 3 & 10 & - & - & - & - \\
\hline
\end{tabular}

ductor muscles and are capable of applying harder bites (Herrel et al., 1996, 1999a, 2007; Huyghe et al., 2009). Bite force across lizard species can be predicted on the base of the shape of the head. Width and height of the head are the most important indicators of the ability of a lizard to bite hard (Herrel et al., 1999a, 2001a, b, 2004; Vanhooydonck et al., 2011), but also the length of the head impacts bite performance, at least in genus Chamaeleolis Duméril \& Bibron, 1837 (Herrel and Holanova, 2008). Considering the very small overall size of A. kitaibelii and the shape of its head, it is likely that its main strategy to immobilise prey is not based on hard biting (Anderson et al., 2008), and it was mentioned briefly that that Ablepharus Fitzinger, 1823 shakes its prey after uptake (Dauth, 1983). In this work we use high-speed video cinematography to analyse this behaviour in detail. In such shaking movements, forces generated post-cranially have to be transmitted to the head of the predator and on the prey, therefore we additionally studied the morphology of the joints between the elements of the cranio-cervical system (sensu Weisgram and Zweers, 1987). We compare the bauplan of the cranio-cervical joint of A. kitaibelii to other lepidosaurs from different taxa and discuss possible relations between the morphology of the occipital-atlasaxis complex and species ecology.

\section{Material and methods}

The object in this study A. kitaibelii is a very small lizard with snout-vent length up to $55.5 \mathrm{~mm}$ in females (Ljubisavljević et al., 2002) and $47.5 \mathrm{~mm}$ in males (VV and NT, unpubl. data). The species inhabits dry bushy meadows, and oak forests in South-east Europe and Western and Central Asia Minor (Schmidtler, 1997; Stojanov et al., 2011). In Bulgaria A. kitaibelii is distrib- uted sporadically on the territory of the country up to $1550 \mathrm{~m}$ altitude but is absent in the low valleys and deforested terrains (Tzankov, 2007). Data on the diet of the species are scarce and partly controversial. It was reported that A. kitaibelii feeds on small insects and their larvae (Fejervary, 1912) and more generally on members of seven different arthropod orders (Herczeg et al., 2007). It was also reported that A. kitaibelii does not feed on big and hard prey (Angelov et al., 1966).

In order to fill the gap of information concerning the diet of the species we investigated the food spectrum in A. kitaibelii by analysing excrements from a total of 25 wild individuals inhabiting three Bulgarian localities. Preliminary data for the food spectrum of the species were taken by examination of the excrements of live individuals. For the purpose, live specimens were caught and kept a few days in boxes and after that they were released back into the wild. Specimens were caught in Zemen (14.09.10, relative coordinates N42.47 E22.72, 20 faeces from 7 specimens); Belovets (29.07.10, relative coordinates N43.80 E26.43, 8 faeces from 8 specimens); and Pancharevo (15.09.10, relative coordinates N42.58 E23.43, 2 faeces from 2 specimens). The chitin rests in the faeces were identified to order level by using a dissection microscope.

In indoor experiments, three adult wild skinks (body length 35,46 and $53 \mathrm{~mm}$ ) were filmed in a glass terrarium $(40 \times 20 \times 03 \mathrm{~cm})$. Six shaking clusters (groups of prey shakes) were filmed per individual in lateral view, using a Casio EX-FH20 high-speed camera (210 frames per second). As food items we used Tenebrio larvae with a total length of $18( \pm 3) \mathrm{mm}$ (over twice the length of the lizard`s skull). Kinematic analysis was performed by using SIMI MatchiX () SRM software. Kinematic data was tested with Shapiro-Wilk test for normal distribution. The p-value was less than the chosen alpha level $(p<0.05)$ for one individual, then the null hypothesis 

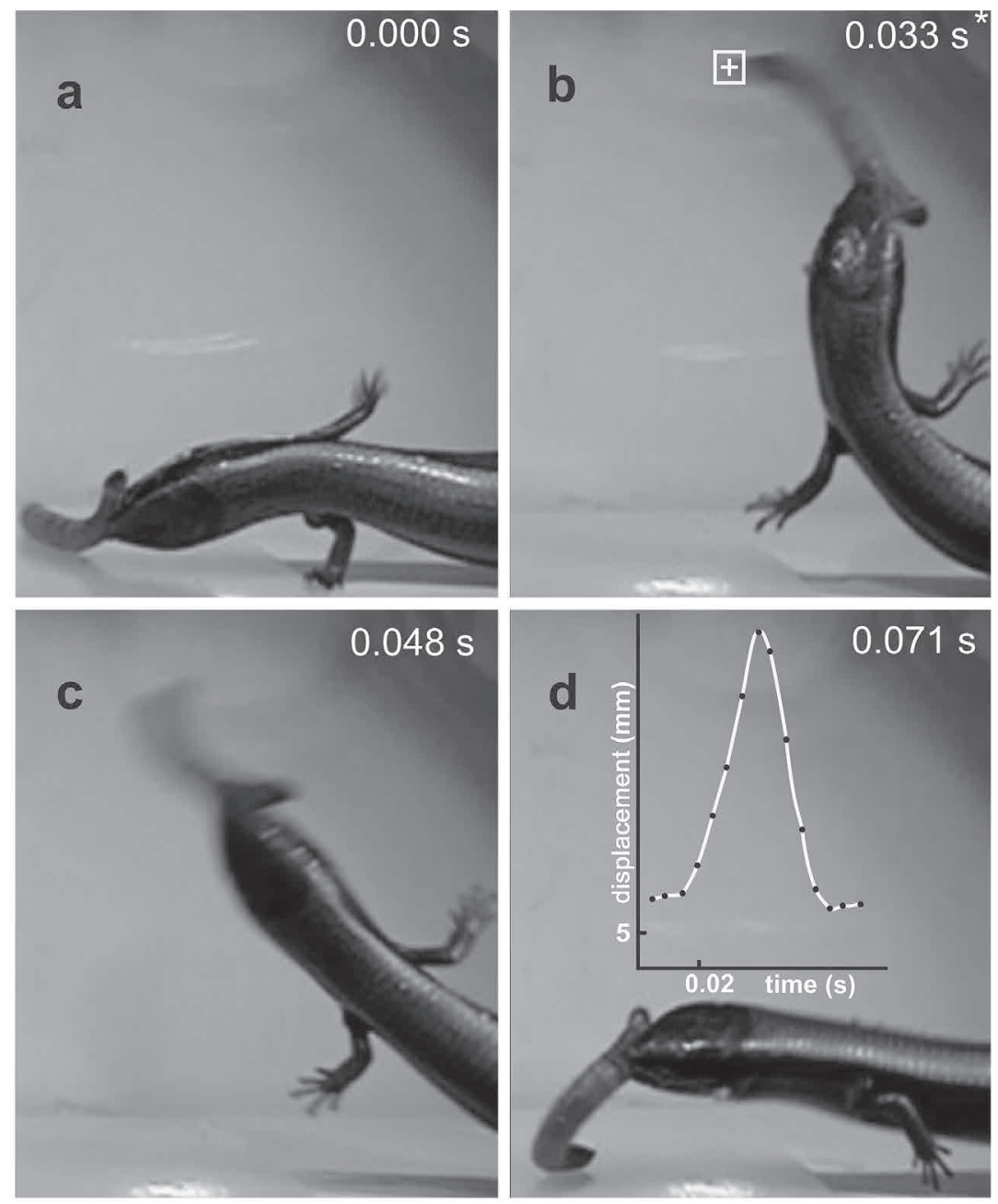

Fig. 2. Prey battering against the substrate. Ablepharus kitaibelii is able to hit its prey against the substrate with an average speed of more than $2 \mathrm{~m} / \mathrm{s}$. (a,b) The prey is lifted. (c, d) The prey is hit against the substrate. (d) shows the kinetmatic profile of the marker displayed in (b). was rejected and Kruskal-Wallis test with a Bonferroni correction was later performed for a whole dataset. As no statistically significant difference between individuals was found, results from the three specimens were pooled and standard descriptive statistics including mean, range and standard deviation was performed.

We investigated the skull morphology using both high-resolution microscopic computed tomography $(\mu \mathrm{CT})$ and histology. For $\mu \mathrm{CT}$, an adult specimen was fixed in $4 \%$ formaldehyde and then washed and preserved in $70 \%$ ethanol. It was mounted in a plastic tube in $70 \%$ ethanol and scanned using a SCANCO $\mu \mathrm{CT} 35$ with $70 \mathrm{keV}$ source voltage and $114 \mu \mathrm{A}$ intensity. Projections were recorded with an angular increment of $0.18^{\circ}$, and reconstructed slices measured $2048 \times 2048$ at a voxel resolution of $3.5 \mu \mathrm{m}$. The reconstructed image was visualised via volume rendering using Drishti (Limaye, 2012).
For histology, one adult specimen was fixed in Bouins fluid. For decalcification it was preserved in the fixative for 20 days. After dehydration it was embedded in paraffin and sagittaly sectioned (section thickness 3 $\mu \mathrm{m})$ with a Thermo Scientific ${ }^{\mathrm{TM}}$ HM355S-2 microtome. Sections were stained with haematoxylin and eosin in order to get good overall contrast for bones, articular cartilages and the articular capsule and to analyse the cranio-cervical-joint on tissue level. Colour micrographs were taken with a Zeiss AxioImager Z2 microscope.

In order to assess the differences in cranio-cervical morphology in major squamate groups, we juxtaposed a recent molecular phylogeny of squamates (Pyron et al., 2013) to a recent morphological tree (Gauthier et al., 2012), and plotted the abundance of different states of cranio-cervical morphology for each group on these trees. Data for most squamate groups was available 
Table 2. Kinematic analysis of the shake clusters. This table shows average durations of prey shaking clusters and single prey shakes as well as the number of shakes per shaking cluster for three specimens.

\begin{tabular}{llll}
\hline Variables & Specimen 1 & Specimen 2 & Specimen 3 \\
\hline Duration of a shake cluster (s) & $0.182 \pm 0.041$ & $0.162 \pm 0.039$ & $0.190 \pm 0.031$ \\
Minimal-maximal duration (s) & $0.124-0.233$ & $0.114-0.214$ & $0.143-0.228$ \\
Number of analysed clusters & $\mathrm{n}=6$ & $\mathrm{n}=6$ & $\mathrm{n}=6$ \\
Number of shakes in a cluster & $3.333 \pm 0.516$ & $3.000 \pm 0.624$ & $3.500 \pm 0.548$ \\
Minimal-maximal number of shakes & $3-4$ & $2-4$ & $3-4$ \\
Number of analysed clusters & $\mathrm{n}=6$ & $\mathrm{n}=6$ & $\mathrm{n}=6$ \\
Duration of single shakes (s) & $0.053 \pm 0.015$ & $0.051 \pm 0.011$ & $0.052 \pm 0.008$ \\
Minimal - maximal duration (s) & $0.033-0.095$ & $0.038-0.080$ & $0.038-0.067$ \\
Total number of analysed shakes & $\mathrm{n}=20$ & $\mathrm{n}=18$ & $\mathrm{n}=21$ \\
\hline
\end{tabular}

from the digital database Digimorph (www.digimorph. org; Humphries, 2004). In total we analysed the craniocervical morphology of 110 squamate species based on Digimorph datasets. Data on cranio-cervical morphology of Rhynchocephalia (Sphenodon punctatus) was taken from Jones et al. (2009).

\section{Results}

\section{Analysis of diet}

Analysis of the diet of wild populations showed that $A$. kitaibelii feeds on various arthropod taxa (Araneae, Lithobiomorpha, Hymenoptera, Coleoptera, Hemiptera, Diptera, Pseudoscorpiones and Lepidoptera) including noxious spiders and chilopods (Table 1).

\section{Feeding kinematics}

Feeding experiments showed that $A$. kitaibelii uses jaw prehension to catch its prey. Initially, the anterior part of the body is lifted and the head is bent ventrally (Fig. 1I). Food uptake is immediately followed by prey shaking. Single prey shakes were very fast in all three investigated specimens (durations in average $0.052 \pm 0.01 \mathrm{~s}$ ) and relatively uniform in their kinematics (Table 2). The number and the duration of the shakes within shaking clusters did not differ significantly among the individuals ( $p>0.05$ for all pairs). At the beginning of each shaking cluster, $A$. kitaibelii rises up its chest and the fore limbs, while the hind limbs and the tail stay in contact to the substrate. Next it stretches the fore limbs laterally and twists the neck and the head sidewise. Afterwards A. kitaibelii hits the prey against the substrate or shakes it in the air. Subsequently the body is twisted in the alternative direction (see Fig. 1II, Supplementary video 1). The maximal number of shakes grouped in a shaking cluster was 4 and the minimal number was 2 $(3.28 \pm 0.54)$. In two prey shaking film sequences, the prey was lifted and then 'battered' laterally against the substrate (Fig. 2, Supplementary video 2). On the base of the kinematical profile of prey movement measured at the most distant part of the prey item (Fig. 2) we calculated that the lizard is able to accelerate the larvae and hit it against the substrate with an average speed of over $2 \mathrm{~m} / \mathrm{s}$ in less than 25 milliseconds (see Fig. 2d, Supplementary video 2).

\section{Morphology of the cranio-cervical-joint}

Ablepharus kitaibelii possesses a well-developed synovial joint formed by three bones: the basioccipital, the atlas, and the cylindrically elongated odontoid process of the axis (Fig. 3d). The basioccipital is a thin bone, but it is markedly thickened at the occipital condyle (Fig. 3a, c) that has a ventrally curved groove in which the odontoid process lies. The atlas articulates anteriorly with the single occipital condylus and posteriorly with the axis (Figs 3b, d, 4), and its neural arches do not fuse dorsally (Figs 3a, c, 4). Altogether the occipito-atlanto-axial complex forms a well-developed pivot joint (Fig. 3b).

\section{Discussion}

\section{Analysis of diet}

Our analysis of A. kitaibelii excrements from three different Bulgarian populations showed that $63.3 \%$ of found food items belonged to either Araneae or 


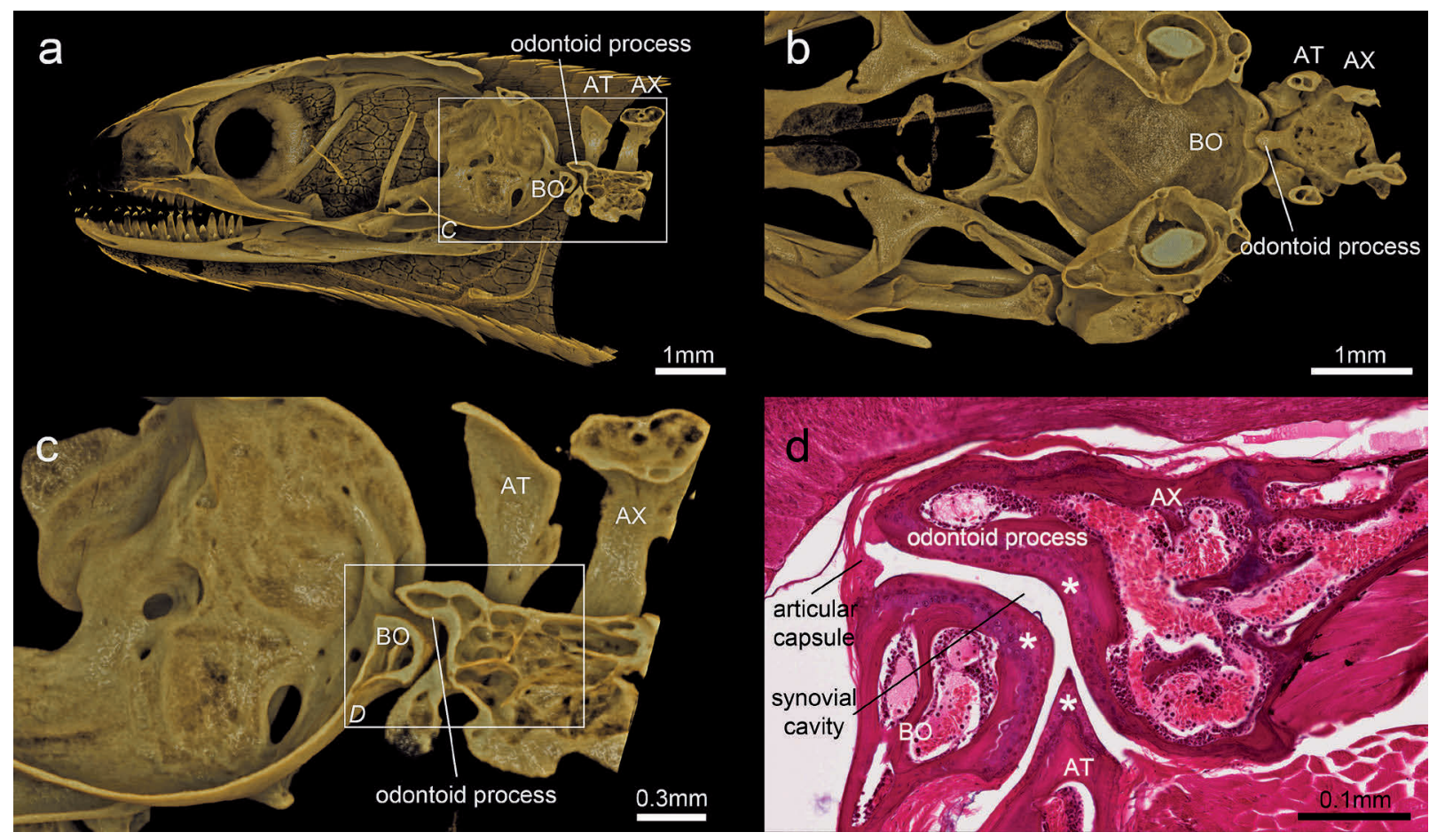

Fig. 3. Morphology of the occipito-atlanto-axial complex in Ablepharus kitaibelii. (a) Sagittal section of the skull based on microCT scan. (b) Detailed dorsal view of the occipito-atlanto-axial based on microCT scan. (c) Lateral section through the occipito-atlantoaxial joint based on microCT. (d) Histological section representing the sagittal plane of the occipito-atlanto-axial joint. AT, atlas; AX, axis; $\mathrm{BO}$, basioccipital; * articular cartilage.

Hemiptera. The found food spectrum was similar to previous data (Angelov et al., 1966; Herczeg et al., 2007) on A. kitaibelii diet (Table 1). Angelov et al. (1966) dissected the stomachs from individuals of two localities of Bulgaria, collected in May. Herczeg et al. (2007) studied the food spectrum of A. kitaibelii populations in Hungary at different seasons (spring and summer) by flushing the stomach content. A comparison of the three datasets shows on the one hand that two groups of arthropods reported in earlier studies, Pseudoscorpiones and Lepidoptera, were not found in the present study. On the other hand, the present study for the first time reports Lithobiomorpha as part of the diet of A. kitaibelii. Interestingly, the smallest of all skink species, Menetia greyi Gray, 1845, also feeds on noxious prey (Pianka, 2011).

Feeding kinematics and morphology of the craniocervical-joint

Ablepharus kitaibelii is able to feed on relatively large and even harmful prey, despite its minute body size and its fragile skull. High-speed video sequences showed that the prey is immobilised by vigorous shaking and battering movements (Fig. 1II and Supplementary videos), thus confirming previous observations (Dauth, 1983). The position of the body and the head of the lizards during these fast movements suggested that forces created by twisting of the trunk are transmitted to the prey via the predators head. The morphology of the cranio-cervical joint shows that the occipito-atlantoaxial complex of A. kitaibelii functionally represents a well-developed pivot joint.

In amniotes, the first two cervical vertebrae (atlas and axis) are typically modified to support the movements of the skull. In most extant amniote groups, the atlas is ring-shaped and lacks a pleurocentrum, thus consisting of the neural arches and the first intercentrum, while the first pleurocentrum is attached to the axis and forms the odontoid process. Such a situation is found in lepidosauria, crocodiles, birds, and mammals, while chelonians show a more plesiomorphic condition (Romer, 1956; Hoffstetter and Gasc, 1969; Wake, 1992).

Plesiomorphic for amniotes, a single convex occipital condyle forms a ball-and-socket joint with the first 


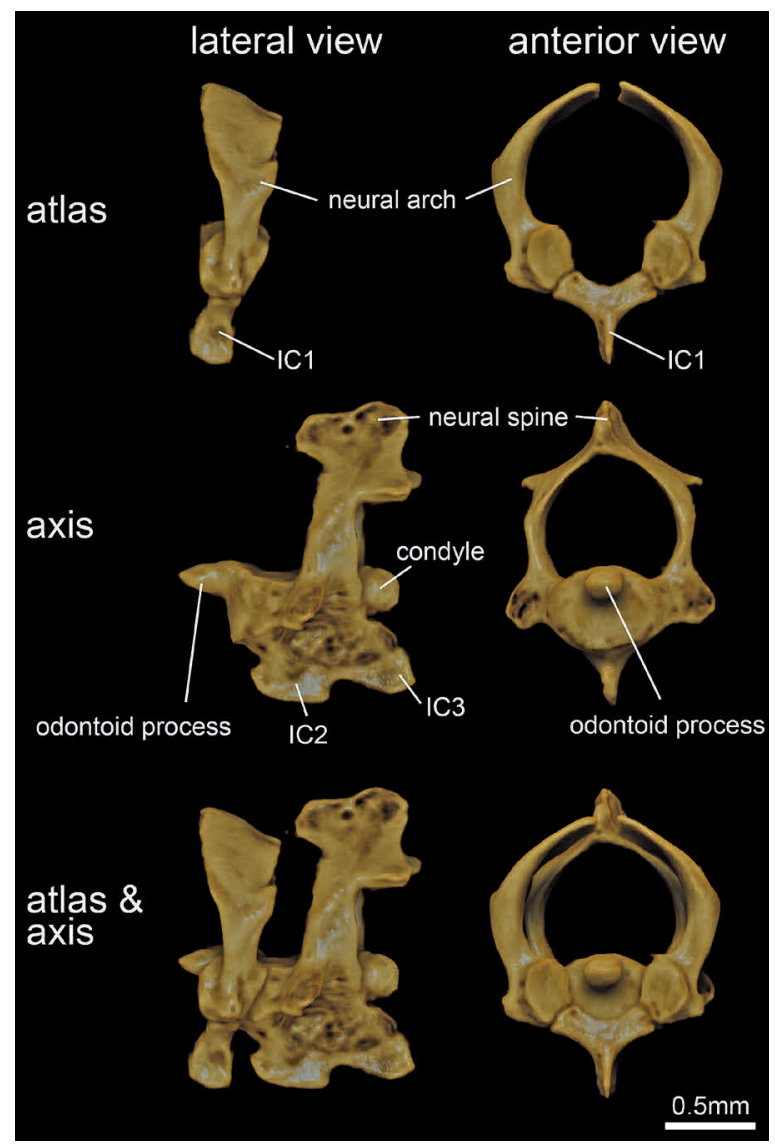

Fig. 4. Atlas and axis of Ablepharus kitaibelii. The atlas is a slender ring formed by the first intercentrum (IC1) and the two neural arches, which do not fuse dorsally. The first pleurocentrum (odontoid process) is fused to the stout axis, which also contains the second and third intercentrum (IC2 and IC3).

two cervical vertebrae, which allows for rotation in basically all directions. Such ball-and-socket joints can still be found in various amniote groups (Kasper, 1903; Hoffstetter and Gasc, 1969; Weisgram and Zweers, 1987). Additionally in some groups, most markedly in mammals, the odontoid process is elongated and acts as a pivot in turning the head (Wake, 1992). In the following we call this a 'functional odontoid process', and a functional odontoid process evolved homoplastically in different amniote lineages (Schaeffer et al., 1972). The functionality and morphology of the odontoid process is most specialized in mammals, where it allows a lateral movement between atlas and axis, while the joint between the double occipital condyles and the atlas only allows a vertical movement (Romer, 1956). No reptile has evolved precisely the mammalian type of atlas and axis, still various specializations have evolved within squamates (Romer, 1956). In many lizards the odontoid process comes to lie within a trough on the dorsal surface of the occipital condyle (Rieppel, 1980), while the atlas articulates via a concave facet to the occipital condyle.

In A. kitaibelii, the morphology of the odontoid process is highly distinct. In its slim cylindrical appearance (Fig. 3b) it acts as a highly efficient pivot for lateral head rotation. Since in reptiles the atlas is more or less locked to the axis (Hoffstetter and Gasc, 1969), rotation occurs between the odontoid process and the skull, while in mammals rotation is between the odontoid process and the atlas. Considering the fast and vigorous head rotation during prey shaking, we hypothesise that the cylindrical odontoid process stabilises the cranio-cervical complex during prey shaking and battering and improves the transmission of postcranially created muscle forces onto the head. While the occipito-atlanto-axial joint stabilises the craniocervical joint during lateral rotation, it likely restricts the ability of the species to flex the cranium ventrally against the atlanto-axial complex (Fig. 1I).

\section{Differences in cranio-cervical morphology between} major squamate groups

To our knowledge this is the first study that correlates feeding kinematics to cranio-cervical morphology in lizards. Considering the high variability in morphology of the odontoid process and the fact that some species totally lack an odontoid process e.g. the snake Uropeltis Cuvier, 1829 (Hoffstetter and Gasc, 1969), we think that linking feeding kinematics and locomotion to cranio-cervical morphology across various squamate groups should be a fruitful endeavour. In order to estimate the variability in cranio-cervical joints we screened $\mu \mathrm{CT}$ datasets from 110 representatives of squamata (S3 Table) from the digital database Digimorph (www.digimorph.org, Humphries, 2004). This screening revealed the presence of a functional odontoid process in 90 of these species. The analysis also showed that highly specialised pivot joints with a slim cylindrical or conoid odontoid process as described here for A. kitaibelii are very rare, but can be found in some iguanians (e.g. Uma scoparia Cope, 1894), some gekkotans (e.g. Lialis burtonis Gray, 1835), or in some teiids (e.g. Aspidoscelis tigris (Baird and Girard, 1852)). In most of the investigated squamate species the odontoid process is stout and blunt, and either pyramidalshaped or round. Such joints can be found in some 
Molecular tree modified from

Morphological tree modified from Pyron et al. 2013

Gauthier et al. 2012

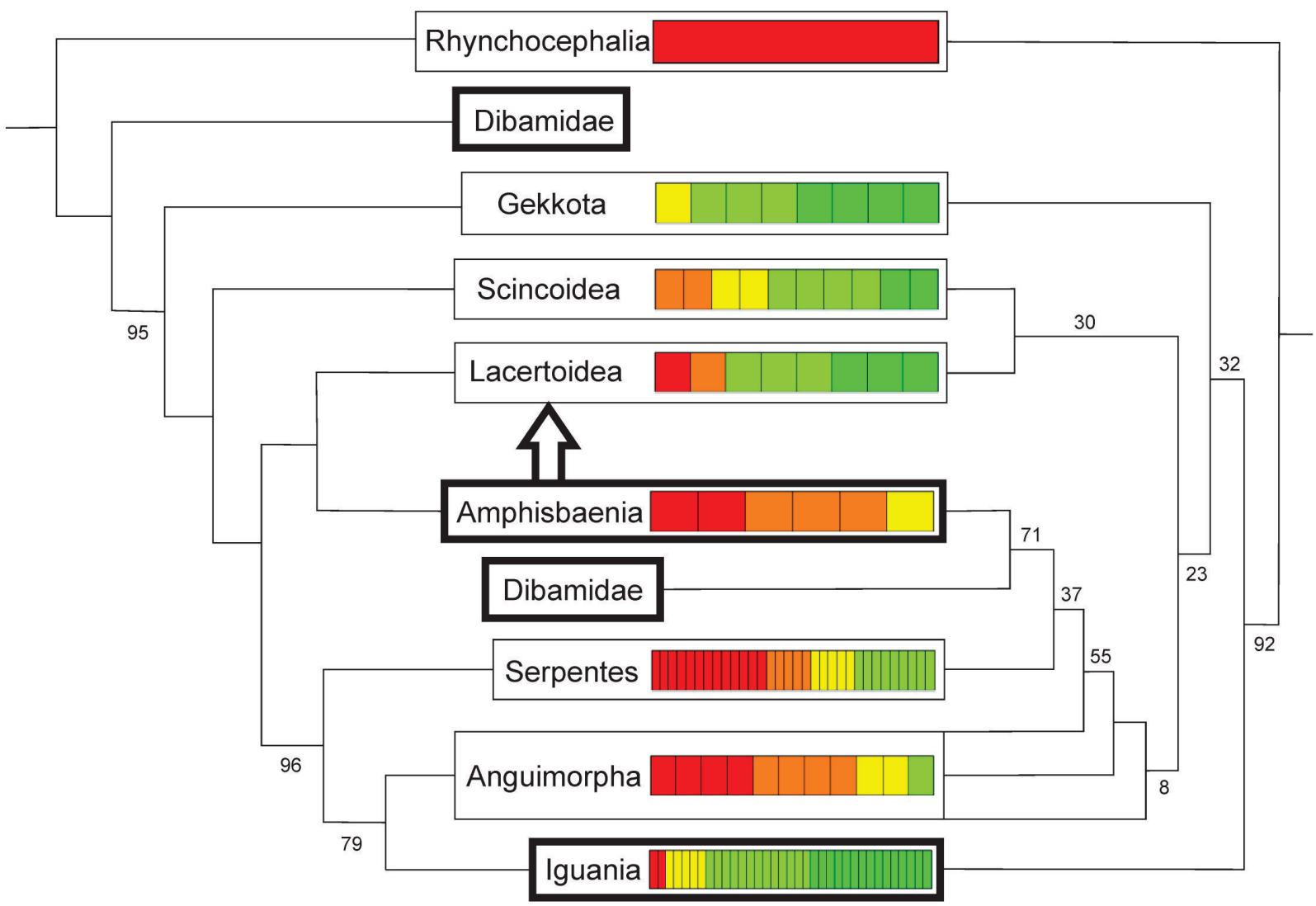

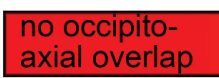

axial overlap

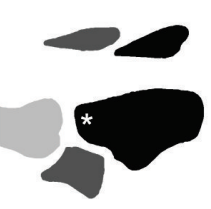

sagittal

slice

dorsal

view

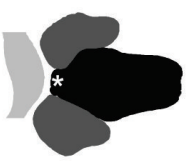

basicoccipital

\section{atlas}

highly specialised occipito-axial joint
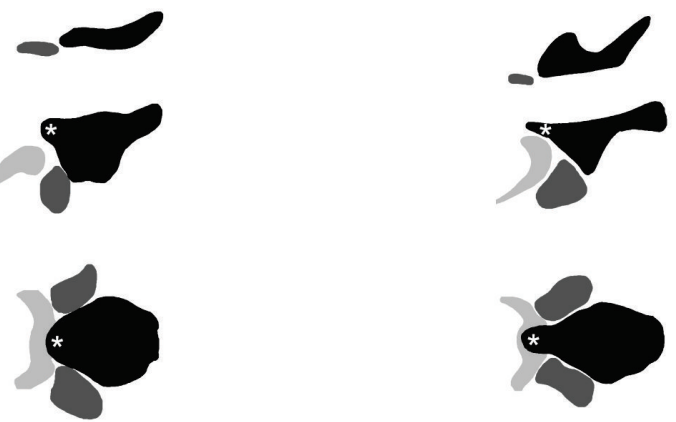

\section{axis}


iguanians (e.g. Anolis carolinensis Voigt, 1832), scincoids (e.g. Amphiglossus splendidus (Grandidier, 1872)), or serpents (e.g. Lachesis muta (Linnaeus, 1766)). Blunt odontoid processes are limited in acting as pivot, thus such joints likely function as an intermediate between a ball-and socket and a specialised pivot joint. Other squamates entirely lack a functional odontoid process, such as some chameleons (e.g. Brookesia brygooi Raxworthy and Nussbaum, 1995), some amphisbaenians (e.g. Amphisbaena fuliginosa Linnaeus, 1758), or some serpents (e.g. Boa constrictor Linnaeus, 1758). Altogether the analysis of the digital datasets showed that the cranio-cervical joint of squamates is extremely variable even within taxa, a fact that warrants thorough functional investigation (see also Cernansky et al., 2014; in chameleons, members of the genus Rhampholeon Werner, 1902 show totally different axis morphology). Although variability is large within major squamate groups, some general trends can be observed. Well-developed joints between occipital and odontoid process are common in iguanians, gekkotans, scincoids, and lacertoids, while they are rather rare in anguimorphs and totally lacking in amphisbaenians (Fig. 5, S3 Table). Therefore, the rareness of well-developed functional pivots in fossorial and legless species may be linked to species ecology e.g. in terms of locomotion.

\section{Conclusions}

Within squamates, highly specialised cranio-cervical joints such as the pivot joint described here evolved in parallel in various groups, and we hypothesise that such joints often represent functional adaptations to specific feeding and locomotion patterns. Linking feeding kinematics and locomotion to cranio-cervical morphology in future studies might further elucidate the function of specialised occipito-atlanto-axial systems. The distribution of cranio-cervical joints in squamate groups shows that functional odontoid processes are rare in fossorial and legless groups.

Recent studies on higher-level squamate phylogeny still show major disagreements between molecular and morphological data (Fig. 5) (Gauthier et al., 2012; Pyron et al., 2013). Based on the high degree of parallel evolution, we think that the analysing of the morphology of the occipito-atlanto-axial complex will not help to resolve these disagreements.

\section{Acknowledgements}

We thank Josef Weisgram, Andreas Wanninger, Martin Glösmann, Georgi Hristov and Thomas Schwaha for technical support and discussion, and Timothy Rowe and the DigiMorph team for establishing and sharing their tremendous database. We also thank two reviewers whose comments helped to improve the manuscript.

\section{References}

Anderson RA, McBrayer LD, Herrel A. 2008. Bite force in vertebrates: opportunities and caveats for use of a nonpareil whole-animal performance measure. Biolological Journal of the Linnean Society 93: 709-720.

Angelov P, Tomov V, Gruev G. 1966. Investigations on the food spectrum of some lizards in Bulgaria.Travaux Scientifique de l'Ecole Superieur - Plovdiv 4: 99-105.

Cernansky A, Boistel R, Fernandez V, Tafforeau P, Nicolas LN, Herrel A. 2014. The atlas-axis complex in Chamaeleonids (Squamata: Chamaeleonidae), with description of a new anatomical structure of the skull. Anatomical record 297: 369-396.

da Silva JM, Herrel A, Measey GJ, Tolley KA. 2014. Sexual dimorphism in bite performance drives morphological variation in chameleons. PloS One 9: e86846.

\footnotetext{
Fig. 5. Variability of the occipito-atlanto-axial complex in major squamate groups. The variability of the occipito-atlanto-axial complex is plotted on two recent trees of higher-level squamate phylogeny. Left side: generalized tree (numbers at nodes are SHL values greater than 50\%) presented by Pyron et al. (2013). Right side: generalized maximum parsimony strict consensus tree (numbers at nodes are BS values) presented by Gauthier et al. (2012). Bold frames indicate current disagreements between molecular and morphological data. In total we screened 110 digimorph (Humphries, 2004) microCT datasets for the presence and the morphology of a functional odontoid process (an odontoid process that acts as pivot in turning the head). By looking at sagittal and horizontal microCT slices we classified species into five groups according to the degree of overlap between the odontoid process and the basioccipital $(1$ (red) $=$ no overlap, no functional odontoid process; 2 -4 intermediate forms of overlap and odontoid process morphology; 5 (green) = perfect overlap, elongated odontoid process). Functional odontoid processes are common in e.g. iguanians and gekkotans (where they occur in more then $50 \%$ of the analysed species), but they are rare in e.g. amphisbaenians and serpents. Number of species analysed: Iguania $n=35$; Gekkota $n=8$; Lacertoidea $n=8$; Scincoidea $n=10$; Amphisbaenia $n=6$; Serpentes $n=32$; Anguimorpha $n=11$. Data on Rhynchocephalia was taken from Jones et al. (2009). * odontoid process.
} 
Dauth J. 1983. Zum Problem des "Totschüttelns" bei Reptilien unter besonderer Berïcksichtigung der Lacertilia. Dissertation zur Erlangung des Doktorates an der Formal und Naturwissenschaftlichen Fakultät der Universität Wien.

Dauth J. 1986. On preyshaking ("Death-shaking") in Lacertidae. Pp. 593-596 in: Rocek Z, ed., Studies in Herpetology. Prague: Charles University.

Fejervary GJ. 1912. Über Ablepharus pannonicus Fitz. Zoologische Jahrbücher 33: 547-574.

Fitch HS. 1954. Life history and ecology of the five-lined skink, Eumeces fasciatus. University of Kansas Publications, Museum of Natural History 8: 1-156.

Fry BG, Scheib H. 2007. Venom breathing dragons: the molecular diversity of protein toxines in varanid Venoms. Mertensiella 16: 10-24.

Fry BG, Vidal N, Norman JA, Vonk FJ, Scheib H, Ramjan SFR, Kuruppu S, Fung K, Hedges SB, Richardson MK, Hodgson WC, Ignjatovic V, Summerhayes R, Kochva E. 2006. Early evolution of the venom system in lizards and snakes. Nature 439: 584-588.

Fry BG, Wroe S, Teeuwisse W, van Osch MJP, Moreno K, Ingle J, McHenry C, Ferrara T, Clausen P, Scheib H, Winter KL, Greisman L, Roelants K, van der Weerd L, Clemente CJ, Giannakis E, Hodgson WC, Luz S, Martelli P, Krishnasamy K, Kochva E, Kwok HF, Scanlon D, Karas J, Citron DM, Goldstein EJC, Mcnaughtan JE, Norman JA. 2009. A central role for venom in predation by Varanus komodoensis (Komodo Dragon) and the extinct giant Varanus (Megalania) priscus. Proceedings of the National Academy of Sciences of the United States of America 106: 8969-8974.

Fry BG, Winter K, Norman JA, Roelants K, Nabuurs RJA, van Osch MJP, Teeuwisse WM, van der Weerd L, Mcnaughtan JE, Kwok HF, Scheib H, Greisman L, Kochva E, Miller LJ, Gao F, Karas J, Scanlon D, Lin F, Kuruppu S, Shaw C, Wong L, Hodgson WC. 2010. Functional and structural diversification of the anguimorpha lizard venom system. Molecular and Celluar Proteomics 9: 2369-2390.

Gauthier JA, Kearney M, Maisano JA, Rieppel O, Behlke A. 2012. Assembling the squamate tree of life: perspectives from the phenotype and the fossil record. Bulletin of the Peabody Museum of Natural History 53: 3-308.

Herczeg G, Kovacs T, Korsos Z, Torok L. 2007. Microhabitat use, seasonal activity and diet of the snake-eyed skink (Ablepharus kitaibelii fitzingeri) in comparison with sympatric lacertids in Hungary. Biologia 62: 482-487.

Herrel A, Holanova V. 2008. Cranial morphology and bite force in Chamaeleolis lizards - Adaptations to molluscivory? Zoology 111: 467-475.

Herrel A, VanDamme R, DeVree F. 1996. Sexual dimorphism of head size in Podarcis hispanica atrata: Testing the dietary divergence hypothesis by bite force analysis. Netherlands Journal of Zoology 46: 253-262.

Herrel A, Wauters I, Aerts P, de Vree F. 1997. The mechanics of ovophagy in the beaded lizard (Heloderma horridum). Journal of Herpetology 31: 383-393.

Herrel A, Spithoven L, Van Damme R, De Vree F. 1999a. Sexual dimorphism of head size in Gallotia galloti: testing the niche divergence hypothesis by functional analyses. Functional Ecology 13: 289-297.

Herrel A, Verstappen M, De Vree F. 1999b. Modulatory complexity of the feeding repertoire in scincid lizards. Journal of Comparative Physiology A 184: 501-518.
Herrel A, Meyers JJ, Nishikawa KC, De Vree F. 2001a. The evolution of feeding motor patterns in lizards: Modulatory complexity and possible constraints. American Zoologist 41: 1311-1320.

Herrel A, Van Damme R, Vanhooydonck B, De Vree F. 2001b. The implications of bite performance for diet in two species of lacertid lizards. Canadian Journal of Zoology 79: 662-670.

Herrel A, Vanhooydonck B, Van Damme R. 2004. Omnivory in lacertid lizards: adaptive evolution or constraint? Journal of Evolutionary Biology 17: 974-984.

Herrel A, McBrayer LD, Larson P. 2007. Functional basis for intersexual differences in bite force in the lizard Anolis carolinensis. Biological Journal of the Linnean Society 91: 111-119.

Hoffstetter R, Gasc J-P. 1969. Vertebrae and ribs of modern reptiles. Pp. 201-310 in: Gans C, Bellairs Ad'A, Parsons TS, eds, Biology of the Reptilia. London and New York: Academic Press.

Honegger RE, Heusser H. 1969. Beitrage zum Verhaltensinventar des Bindenwarans Varanus salvator. Zoologische Garten (NF) 36: 251-260.

Humphries JM. 2004. Digimorph.Org: A digital library of morphology based on high-resolution x-ray computed tomography. Journal of Morphology 260: 300.

Huyghe K, Herrel A, Adriaens D, Tadic Z, Van Damme R. 2009. It is all in the head: morphological basis for differences in bite force among colour morphs of the Dalmatian wall lizard. Biological Journal of the Linnean Society 96: 13-22.

Jones MEH, Curtis N, O’Higgins P, Fagan M, Evans SE. 2009. the head and neck muscles associated with feeding in Sphenodon (Reptilia: Lepidosauria: Rhynchocephalia). Palaeontologia Electronica 12: 1-56.

Kasper A. 1903. Über den Atlas und Epistropheus bei den pleurodiren Schildkröten. Arbeiten aus dem Zoologischen Institut der Universitat Wien 4: 137-172.

Lappin AK, German M. 2005. Feeding behavior modulation in the leopard lizard (Gambelia wislizenii): Effects of noxious versus innocuous prey. Zoology 108: 287-295.

Limaye A. 2012. Drishti-volume exploration and presentation tool. SPIE Proceedings 2012 8506:85060X-85060X.

Ljubisavljević K, Džukić G, Kalezić ML. 2002. Morphological differentiation of the Snake-eyed Skink Ablepharus kitaibelii (Bibron \& Bory, 1833), in the north-western part of the species' range: systematic implications. Herpetozoa 14: 107-121.

McBrayer LD, White TD. 2002. Bite force, behavior, and electromyography in the teiid lizard, Tupinambis teguixin. Copeia 2002: 111-119.

Pianka ER. 2011. Notes on the natural history of the tiny skink Menetia greyi. Western Australian Naturalist 28: 12-17.

Pyron RA, Burbrink FT, Wiens JJ. 2013. A phylogeny and revised classification of Squamata, including 4161 species of lizards and snakes. BMC Evolutionary Biology 13: 1-53.

Rieppel O. 1980. The phylogeny of anguinomorph lizards. Birkhäuser Verlag, Basel, Boston, Stuttgart.

Roloff E. 1957. Meine Bekanntschaft mit dem Tokeh (Gecko gecko). Aquaristik 3: 133-135.

Romer AS. 1956. The osteology of the reptiles. University of Chicago Press, Chicago.

Ross CF, Eckhardt A, Herrel A, Hylander WL, Metzger KA, Schaerlaeken V, Washington RL, Williams SH. 2007. Modulation of intra-oral processing in mammals and lepidosaurs. Integrative and Comparative Biology 47: 118-136. 
Schaeffer B, Hecht MK, Eldridge N. 1972. Phylogeny and paleontology. Pp. 31-45 in: Dobzhansky T, Hecht MK, Steere WC, eds, Evolutionary Biology Vol 6. Appleton-CenturyCrofts, New York.

Schaerlaeken V, Holanova V, Boistel R, Aerts P, Velensky P, Rehak I, Andrade DV, Herrel A. 2012. Built to bite: feeding kinematics, bite forces, and head shape of a specialized durophagous lizard, Dracaena guianensis (Teiidae). Journal of Experimental Zoology, Part A 317: 371-381.

Schmidtler JF. 1997. Die Ablepharus kitaibelii - Gruppe in SüdAnatolien und benachbarten Gebieten. Herpetozoa 10: 35-63.

Schwenk K. 2000. Feeding in lepidosaurs. Pp. 175-291 in: Schwenk K, ed., Feeding: Form, function, and evolution in tetrapod vertebrates. San Diego: Academic Press

Smith KK. 1982. An Electromyographic Study of the function of the jaw adducting muscles in Varanus exanthematicus (Varanidae). Journal of Morphology 173: 137-158.

Stojanov AJ, Tzankov N, Naumov B. 2011. Die Amphibien und Reptilien Bulgariens. Chimaira, Frankfurt am Main, Germany.

Tzankov N. 2007. European copper skink (Ablepharus kitaibelii). Pp. 86-87 in: Biserkov V, ed. A Field Guide to Amphibians and Reptiles of Bulgaria. Sofia: Green Balkans.
Vanhooydonck B, Boistel R, Fernandez V, Herrel A. 2011. Push and bite: trade-offs between burrowing and biting in a burrowing skink (Acontias percivali). Biological Journal of the Linnean Society 102: 91-99.

Wake DB. 1992. The endoskeleton: the comparative anatomy of the vertebral column and ribs. Pp. 192-237. in: Wake MH, ed., Hyman's Comparative Vertebrate Anatomy. Chicago: University Of Chicago Press.

Weinstein SA, Smith TL, Kardong KV. 2009. Reptile venom glands form, function, and future. Pp. 65-91 in: Mackessy SP, ed., Handbook of Venoms and Toxins of Reptiles. London, New York: Taylor \& Francis Group, Boca Raton.

Weisgram J, Zweers GA. 1987. Avian cranio-cervical systems 2. Arthrology of the occipito-cervical system in the mallard (Anas platyrhynchos L). Acta Morphologica NeerlandoScandinavica 25: 157-166.

Received: 2 August 2014

Revised and accepted: 31 October 2014

Published online: 30 January 2015

Editor: F. Galis

\section{Online supplementary material}

S1. Video: This movie shows a prey shaking cluster typical for Ablepharus kitaibelii when feeding on Tenebrio larvae.

S2. Video: In some sequences, prey immobilization behaviour included battering of prey items against the substrate.

S3. Table: Variability of the occipito-atlanto-axial complex in major squamate groups. 
Supplementary Table 1: Variability of the occipito-atlanto-axial complex in major squamate groups. In total we screened 110 digimorph (Humphries, 2004) microCT datasets for the presence and the morphology of a functional odontoid process (an odontoid process that acts as pivot in turning the head). By looking at sagittal and horizontal microCT slices we classified species into five groups according to the degree of overlap between the odontoid process and the basioccipital (1 (red) = no overlap, no functional odontoid process; $2-4$ intermediate forms of overlap and odontoid process morphology; 5 (green) = perfect overlap, elongated odontoid process, see also Figure 5). Number of species analysed: Iguania $n=35$; Gekkota n=8; Lacertoidea n=8; Scincoidea $n=10$; Amphisbaenia n=6; Serpentes $n=32$; Anguimorpha $\mathrm{n}=11$. Data on Rhynchocephalia was taken from Jones et al. (2009).

\begin{tabular}{lcc} 
species & $\begin{array}{r}\text { Amphisbaenia }(\mathbf{n}=\mathbf{6}) \\
\text { data source }\end{array}$ & occipito-axial joint \\
\hline Amphisbaena fuliginosa & Digimorph & 1 \\
Trogonophis wiegmanni & Digimorph & 1 \\
Bipes biporus & Digimorph & 2 \\
Bipes canaliculatus & Digimorph & 2 \\
Rhineura floridana & Digimorph & 2 \\
Diplometopon zarudnyi & Digimorph & 3
\end{tabular}

\begin{tabular}{lcc} 
species & $\begin{array}{c}\text { Anguimorpha }(\mathbf{n}=\mathbf{1 1}) \\
\text { data source }\end{array}$ & occipito-axial joint \\
\hline Heloderma horridum & Digimorph & 1 \\
Heloderma suspectum & Digimorph & 1 \\
Pseudopus apodus & Digimorph & 1 \\
Shinisaurus crocodilurus & Digimorph & 1 \\
Lanthanotus borneensis & Digimorph & 2 \\
Varanus exanthematicus & Digimorph & 2 \\
Xenosaurus grandis & Digimorph & 2 \\
Celestus enneagrammus & Digimorph & 3 \\
Varanus acanthurus & Digimorph & 3 \\
Elgaria multicarinata & Digimorph & 4
\end{tabular}

\begin{tabular}{lcc} 
species & $\begin{array}{c}\text { Gekkota }(\mathbf{n}=\mathbf{8}) \\
\text { data source }\end{array}$ & occipito-axial joint \\
\hline Eublepharis macularius & Digimorph & 3 \\
Coleonyx variegatus & Digimorph & 4 \\
Gekko gecko & Digimorph & 4 \\
Rhacodactylus auriculatus & Digimorph & 4 \\
Delma borea & Digimorph & 5 \\
Gonatodes albogularis & Digimorph & 5 \\
Lialis burtonis & Digimorph & 5 \\
Phelsuma lineata & Digimorph & 5
\end{tabular}




\begin{tabular}{|c|c|c|}
\hline \multicolumn{3}{|c|}{ Iguania $(n=35)$} \\
\hline species & data source & occipito-axial joint \\
\hline Brookesia brygooi & Digimorph & 1 \\
\hline Chamaeleo laevigatus & Digimorph & 1 \\
\hline Anolis carolinensis & Digimorph & 3 \\
\hline Leiosaurus catamarcensis & Digimorph & 3 \\
\hline Physignathus cocincinus & Digimorph & 3 \\
\hline Plica plica & Digimorph & 3 \\
\hline Zapsosaurus sceliphros $\dagger$ & Digimorph & 3 \\
\hline Brachylophus fasciatus & Digimorph & 4 \\
\hline Crotaphytus collaris & Digimorph & 4 \\
\hline Enyalioides laticeps & Digimorph & 4 \\
\hline Gambelia wislizenii & Digimorph & 4 \\
\hline Isodontosaurus gracilis $†$ & Digimorph & 4 \\
\hline Oplurus cyclurus & Digimorph & 4 \\
\hline Phrynosoma platyrhinos & Digimorph & 4 \\
\hline Pogona vitticeps & Digimorph & 4 \\
\hline Polychrus marmoratus & Digimorph & 4 \\
\hline Pristidactylus torquatus & Digimorph & 4 \\
\hline Uranoscodon superciliosus & Digimorph & 4 \\
\hline Uromastyx aegyptius & Digimorph & 4 \\
\hline Urostrophus vautieri & Digimorph & 4 \\
\hline Agama agama & Digimorph & 5 \\
\hline Basiliscus basiliscus & Digimorph & 5 \\
\hline Calotes emma & Digimorph & 5 \\
\hline Chalarodon madagascariensis & Digimorph & 5 \\
\hline Corytophanes cristatus & Digimorph & 5 \\
\hline Dipsosaurus dorsalis & Digimorph & 5 \\
\hline Leiocephalus barahonensis & Digimorph & 5 \\
\hline Leiolepis belliana & Digimorph & 5 \\
\hline Liolaemus bellii & Digimorph & 5 \\
\hline Petrosaurus mearnsi & Digimorph & 5 \\
\hline Phymaturus palluma & Digimorph & 5 \\
\hline Sceloporus variabilis & Digimorph & 5 \\
\hline Stenocercus guentheri & Digimorph & 5 \\
\hline Uma scoparia & Digimorph & 5 \\
\hline Uta stansburiana & Digimorph & 5 \\
\hline
\end{tabular}

\begin{tabular}{lcc} 
Lacertoidea $(\mathbf{n}=\mathbf{8})$ & \\
species & data source & occipito-axial joint \\
\hline Tupinambis teguixin & Digimorph & 1 \\
Lacerta viridis & Digimorph & 2 \\
Callopistes maculatus & Digimorph & 4 \\
Takydromus ocellatus & Digimorph & 4 \\
Teius teyou & Digimorph & 4 \\
Aspidoscelis tigris & Digimorph & 5 \\
Colobosaura modesta & Digimorph & 5 \\
Pholidobolus montium & Digimorph & 5
\end{tabular}




\begin{tabular}{rcc} 
Rhynchocephalia $(\mathbf{n}=\mathbf{1})$ & \\
species & data source & occipito-axial joint \\
\hline Sphenodon punctatus & Jones et al. (2009) & 1
\end{tabular}

\begin{tabular}{lcc} 
species & $\begin{array}{c}\text { Scincoidea }(\mathbf{n}=\mathbf{1 0}) \\
\text { data source }\end{array}$ & occipito-axial joint \\
\hline Lepidophyma flavimaculatum & Digimorph & 2 \\
Scincus scincus & Digimorph & 2 \\
Amphiglossus splendidus & Digimorph & 3 \\
Brachymeles gracilis & Digimorph & 3 \\
Cordylosaurus subtesselatus & Digimorph & 4 \\
Cordylus mossambicus & Digimorph & 4 \\
Tiliqua scincoides & Digimorph & 4 \\
Zonosaurus ornatus & Digimorph & 4 \\
Eugongylus rufescens & Digimorph & 5 \\
Sphenomorphus solomonis & Digimorph & 5
\end{tabular}

\begin{tabular}{|c|c|c|}
\hline \multicolumn{3}{|c|}{ Serpentes $(n=32)$} \\
\hline species & data source & occipito-axial joint \\
\hline Anilius scytale & Digimorph & 1 \\
\hline Anomochilus leonardi & Digimorph & 1 \\
\hline Aspidites melanocephalus & Digimorph & 1 \\
\hline Boa constrictor & Digimorph & 1 \\
\hline Calabaria reinhardtii & Digimorph & 1 \\
\hline Casarea dussumieri & Digimorph & 1 \\
\hline Cylindrophis ruffus & Digimorph & 1 \\
\hline Eryx colubrinus & Digimorph & 1 \\
\hline Lichanura trivirgata & Digimorph & 1 \\
\hline Loxocemus bicolor & Digimorph & 1 \\
\hline Tropidophis haetianus & Digimorph & 1 \\
\hline Ungaliophis continentalis & Digimorph & 1 \\
\hline Xenopeltis unicolor & Digimorph & 1 \\
\hline Causus rhombeatus & Digimorph & 2 \\
\hline Leptotyphlops dulcis & Digimorph & 2 \\
\hline Naja naja & Digimorph & 2 \\
\hline Natrix natrix & Digimorph & 2 \\
\hline Python molurus & Digimorph & 2 \\
\hline Coluber constrictor & Digimorph & 3 \\
\hline Lachesis muta & Digimorph & 3 \\
\hline Lampropeltis getula & Digimorph & 3 \\
\hline Liotyphlops albirostris & Digimorph & 3 \\
\hline Typhlops jamaicensis & Digimorph & 3 \\
\hline Agkistrodon contortrix & Digimorph & 4 \\
\hline Amphiesma stolata & Digimorph & 4 \\
\hline Bothrops asper & Digimorph & 4 \\
\hline Laticauda colubrina & Digimorph & 4 \\
\hline Lycophidion capense & Digimorph & 4 \\
\hline Micrurus fulvius & Digimorph & 4 \\
\hline Thamnophis marcianus & Digimorph & 4 \\
\hline Typhlophis squamosus & Digimorph & 4 \\
\hline Xenochrophis piscator & Digimorph & 4 \\
\hline
\end{tabular}

